\title{
Peak Growth Hormone Level Variability during Insulin Tolerance Test in Children with Short Stature
}

\author{
Mohsina Noor Ibrahim², Nadeem Noor ${ }^{1}$, Mehrun Nisa², Taj Muhammad Leghari ${ }^{2}$, Yasir Naqvi Khan ${ }^{2}$ and Jamal \\ Raza $^{2}$ \\ ${ }^{1}$ Department of Pediatric Medicine, National Institute of Child Health, Karachi, Pakistan \\ ${ }^{2}$ Department of Pediatric Medicine, Jinnah Medical \& Dental College, Karachi, Pakistan
}

\begin{abstract}
Objective: To determine the variations in peak growth hormone levels during insulin tolerance test (ITT) in diagnosis of growth hormone deficiency (GHD) in children presenting with short stature.

Study Design: Descriptive study.

Place and Duration of Study: Department of Pediatric Endocrinology, National Institute of Child Health (NICH), from January to December 2018.

Methodology: Clinical records of all children who underwent ITT during the above mentioned period were reviewed. All 348 children of either gender from 2-17 years of age with height more than 2SD below the mean $\left(<3^{\text {rd }}\right.$ percentile) suspected GHD and subjected for ITT were included. Verbal consent was taken from all parents. Children below 2 years and with other causes of Short Stature like hypothyroid, celiac, cardiac, chronic liver, kidney diseases and syndrome were excluded.

Results: Total 348 children were subjected to ITT. Out of these $48.3 \%$ were found to have GH levels $<5 \mathrm{ng} / \mathrm{ml}, 33.6 \% \mathrm{~b} / \mathrm{w} 5-10$ $\mathrm{ng} / \mathrm{ml}$ and $18.1 \%>10 \mathrm{ng} / \mathrm{ml}$. Precisely peak GH levels at different time intervals are $1.1 \%, 19.3 \%, 47.4 \%, 29.9 \%$, and $2.3 \%$ for $0,30,60,90$ and 120 minutes respectively. Mostly peak growth hormone levels were accomplished at 60 minutes followed by 90 and then at 30 minutes. Hypoglycemia was achieved $0.8 \%, 47 \%, 26 \%, 24 \%$ and $1 \%$ at $0,30,60,90$, and 120 minutes.

Conclusion: The $0,30,60$, and 90 minutes samples are adequate to confirm the diagnosis of GH deficiency. This shorter duration of ITT to 90 minutes is cost effective as it decreases the financial burden of unnecessary testing. Additionally, it reduces the risk of side effect like hypoglycemia.
\end{abstract}

Key Words: Short stature, Growth hormone deficiency, Insulin tolerance test.

How to cite this article: Ibrahim MN, Noor N, Nisa M, Leghari TM, Khan YN, Raza J. Peak Growth Hormone Level Variability during Insulin Tolerance Test in Children with Short Stature. J Coll Physicians Surg Pak 2021; 31(09):1081-1084.

\section{INTRODUCTION}

A pediatric patient with short stature and no clinically apparent explanation needs to bereferred to pediatric endocrine clinic to identify the cause. After exclusion of other clinical conditions, which may lead to short stature, a subsequent diagnosis of growth hormone deficiency (GHD) may be made in which GH therapy has been approved. ${ }^{1,2} \mathrm{GH}$ is essential in children for their normal growth and metabolism. Without enough GH, a child grows slowly; and remains much shorter than other children of the same age and gender. ${ }^{3}$ The consequent delay in making the diagnosis can undermine the efficacy of GH treatment, so the appropriate diagnosis should be made and treatment be started as soon as possible. ${ }^{2}$

Correspondence to: Dr. Mohsina Noor Ibrahim, Department of Pediatric Endocrinology, National Institute of Child Health, Karachi, Pakistan

E-mail: mohsinaibrahim@yahoo.com

Received: January 17, 2020; Revised: December 24, 2020;

Accepted: February 24, 2021

DOI: https://doi.org/10.29271/jcpsp.2021.09.1081
Short stature is defined as the height below $0.4^{\text {th }}$ centile of 1990 Growth Reference Chart ${ }^{4}$ or a height more than 2 standard deviation below the mean for that age and gender (which corresponds to a height below the $2.3^{\text {rd }}$ percentile) ${ }^{5}$ In the assessment of GHD, child's medical history and growth charts should be reviewed. Furthermore, both clinical and auxological data are required to know the cause of slow growth. ${ }^{6}$ In addition to auxological parameters, biochemical investigations are also mandatory, such as complete blood count, liver function test, renal biochemistry, and tissue transglutaminase to rule out other causes of reduced growth. To facilitate the diagnosis of GHD, GH stimulation test is performed where the child is given provocative agent to release growth hormone from the pituitary gland. If certain blood level of $\mathrm{GH}$ is not achieved after stimulation, it means the pituitary is not making enough $\mathrm{GH}$. Along with GH stimulation test, insulin growth factor-1(IGF-1, a hormone that reflects $\mathrm{GH}$ levels) and insulin like growth factor binding protein 3 (IGFBP3, a binding protein that binds with IGF-1 with very high affinity) are also important. Moreover, X-ray wrist for the child's bone age, and MRI pituitary to rule out pituitary hypoplasia or other pituitary disorders are also included. ${ }^{2}$ 
Different provocative agents like insulin, arginine, clonidine, glucagon, and $\mathrm{GH}$ releasing hormone (GHRH) are used as potent stimulator of $\mathrm{GH}$ secretion for the diagnosis of growth hormone deficiency. Due to the pulsatile nature of GH secretion, a single blood sample of GH measurement is not informative. ${ }^{4}$

Arginine and clonidine are not available in Pakistan and L-Dopa is not routinely performed for the diagnosis of GHD in children. ${ }^{7}$ Insulin tolerance test (ITT) is an important tests, and having good diagnostic yield; but can lead to serious complications, if not performed correctly. ${ }^{6}$ The recommended time duration of ITT is 120 minutes. $^{\text {? }}$

The aim of this study was to ascertain the variations in peak growth hormone levels during insulin tolerance test for short stature; whether it is with shorter time period, i.e. less than 120 minutes and cost-effective analysis.

\section{METHODOLOGY}

After Ethical Review Board approval, this retrospective study was conducted at the Pediatric Endocrinology Department, National Institute of Child Health, Karachi. Clinical data of children, subjected for ITT from January to December 2018, has been reviewed from the record files. All children aged 2-17 years of either gender, who visited the Pediatric Endocrine Clinic, with complain of short stature having height more than $2.5 \mathrm{SD}$ below the mean $\left(<3^{\text {rd }}\right.$ percentile), were included. In children above 12 years, priming was done by single injection of testosterone intramuscular $25 \mathrm{mg}$ depot, 7-10 days before $\mathrm{GH}$ testing in boys; and $1.25 \mathrm{mg}$ oral conjugated estrogen for 3 days before testing, in girls. ${ }^{8}$ Those children who were less than two years, untreated or inadequately treated hypothyroidism, celiac disease, cardiac disease, chronic liver disease, renal problems and syndromes, were excluded. All selected patients underwent insulin tolerance test (ITT). After taking consent from parents, ITT was performed in the presence of trained staff under strict precautions. Insulin was given 0.1 unit/kg subcutaneously and blood samples were drawn for serum blood glucose and serum growth hormone at $0,30,60,90$, and 120 mins after giving insulin. We also checked all the blood glucose levels on glucometer during ITT for hypoglycemia. In these time intervals, the blood sugar level $<50 \mathrm{mg} / \mathrm{dl}$ or $2 / 3^{\text {rd }}$ of highest blood sugar level achieved, was considered as hypoglycemia. The cut-of level of $\mathrm{GH}<10 \mathrm{ng} / \mathrm{ml}$ was considered as the gold standard for growth hormone deficiency. ${ }^{9}$ Growth hormone level $<5 \mathrm{ng} / \mathrm{ml}$ was considered to be severe GH deficiency; 5-10 $\mathrm{ng} / \mathrm{ml}$ was moderate $\mathrm{GH}$ deficiency, and above $10 \mathrm{ng} / \mathrm{dl}$ was cosidered normal.

The samples of serum blood glucose were analysed by analyser on Dimension RxL and serum growth hormone by ELISA on immulite 1000 at the laboratory of National Institute of Child Health.

Mean and standard deviation values of age and height measurements werecalculated. Frequencies and percentages of qualitative variable like gender were also measured. SPSS version 18 was used for statistical analysis.

\section{RESULT}

A total of 348 children between the ages of 2-17 were subjected to ITT. There were 200 (57.5\%) females and 148 (42.5\%) males. The mean age of the subjects was $10.34 \pm 3.37$ years and mean height was $117.4 \pm 14.53 \mathrm{~cm}$. Half of the children aged 8-12 years; while in the remaining half, $22 \%$ of children were the ages of 2-7 years and $28 \%$ were of $13-17$ years, respectively. Children are closely monitored for their blood sugar levels at fixed time intervals. Maximum number of the children (47.1\%) developed hypoglycemia at 30 minutes of commencement of the test; and the percentage of children developing hypoglycemia decreased in subsequent readings at 60,90 and 120 minutes (Figure 1). Similarly, around $50 \%$ of the children reached peak $\mathrm{GH}$ level at 60 minutes; whereas, $30 \%$ and $20 \%$ reached the peak GH level at 90 and 30 minutes, respectively. Only $2 \%$ childrenachieved peak GH levels at 120 minutes (Tablel).

Table I: Frequency of hypoglycemia and peak GH levels at $0,30,60,90$, and 120 minutes.

\begin{tabular}{|l|c|c|}
\hline Time Interval & $\begin{array}{c}\text { No of children with } \\
\text { blood sugar }<\mathbf{5 0} \mathbf{~ m g / d I} \\
\text { or } \mathbf{2} / \mathbf{3}^{\text {rd }} \text { of } \mathbf{h i g h e s t} \\
\text { blood sugar level }\end{array}$ & $\begin{array}{c}\text { No of children with peak GH } \\
\text { levels after administration } \\
\text { of insulin }\end{array}$ \\
\hline 0 minutes & $3(0.9 \%)$ & $4(1.1 \%)$ \\
\hline 30 minutes & $164(47.1 \%)$ & $67(19.3 \%)$ \\
\hline 60 minutes & $93(26.7 \%)$ & $165(47.4 \%)$ \\
\hline 90 minutes & $84(24.1 \%)$ & $104(29.9 \%)$ \\
\hline 120 minutes & $4(1.1 \%)$ & $8(2.3 \%)$ \\
\hline
\end{tabular}

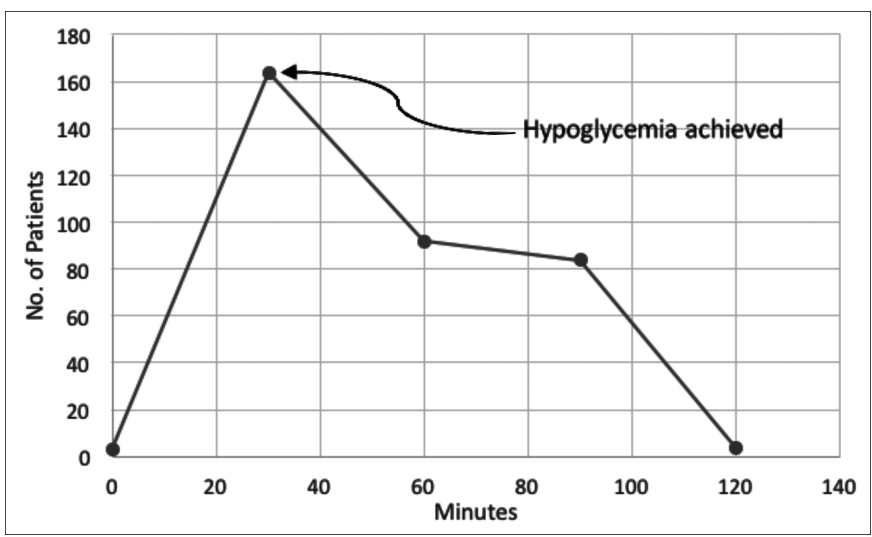

Figure 1: Graph showing the time at which hypoglycemia was achieved.

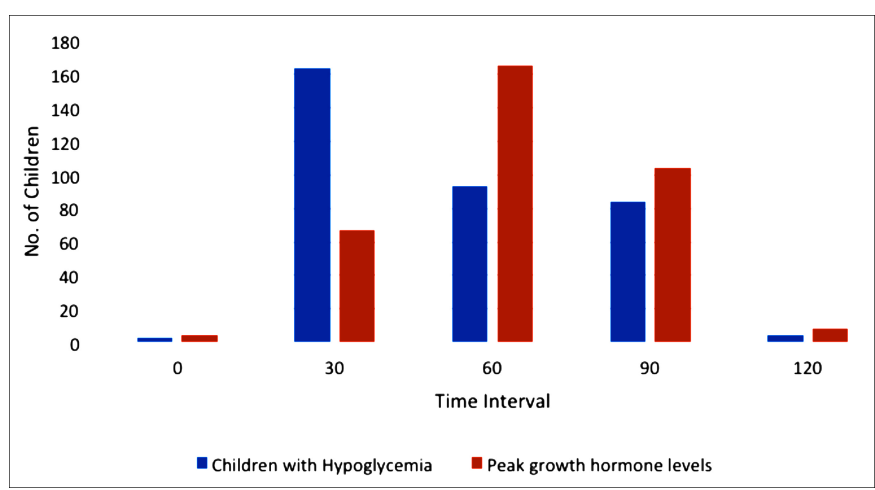

Figure 2: Comparison of peakgrowth hormone levels and hypoglycemia. 
There was a significant difference between blood sugar and peak growth hormone levels at 30,60 and 90 minutes, which were recorded. The peak $\mathrm{GH}$ levels at 120 minute interval were markedly reduced (Figure 2 ).

In the study group of 348 children, 168 (48.3\%) were diagnosed with severe GHD having GH levels <5ng/ml, 117 (33.6\%) with moderate GHD having GH levels b/w 5-10 ng/ml and 63 (18.1\%) with normal GH levels $>10 \mathrm{ng} / \mathrm{ml}$.

\section{DISCUSSION}

Short stature is a common reason for referral to pediatrics endocrine clinics. Classically, short stature is divided into idiopathic short stature (ISS) without any noticeable causes and into the children with growth hormone deficiency (GHD). Recently, ISS is further subdivided into familial short stature (FSS) and non-familial short stature (NFSS) which also includes short children with constitutional delay of growth and puberty. ${ }^{10,11}$

The prevalence of GHD in children is approximately 1 in $4000 .^{12}$ Although GHD is uncommon, it is crucial to diagnose it correctly and as early as possible, as a missed or late diagnosis can impede GH therapy and lead to poor outcomes. ${ }^{12}$ The diagnosis is currently based on clinical assessments like short height, slow growth velocity and needs supporting evidences from radiological and biochemical investigations. ${ }^{12,13}$

To establish the diagnosis of GHD, the assessment of peak $\mathrm{GH}$ levels remains challenging, as random serum $\mathrm{GH}$ concentration has no clinical value due to its pulsatile nature. When the first GHD stimulation test used in 1960 s, a peak GH concentration of $<5 \mathrm{ng} / \mathrm{ml}$ (ug/l) was used to diagnose GHD. Over the years, this cut-off value has raised to $7 \mathrm{ng} / \mathrm{ml}$ (ug/l) and then $10 \mathrm{ng} / \mathrm{ml}(\mathrm{ug} / \mathrm{l})$ due to insufficient validation of clinical studies. ${ }^{13,14}$

Different stimulation tests have been used to establish the diagnosis of GHD. Insulin tolerance test was first used as GH secretion test; later, different pharmacological agent shave been used like glucagon, clonidine, arginine, levodopa and GHRH. The diagnosis of GHD, which obligates $\mathrm{GH}$ replacement therapy, is established with peak GH serum concentration below the cut-off value by at least two $\mathrm{GH}$ stimulation tests. ${ }^{15}$ In one study, done in South Korea, GHD was considered as a serum peak $\mathrm{GH}$ concentration $<10 \mathrm{ng} / \mathrm{ml}$ on provocation with the combination of two separate provocative tests. ${ }^{13}$ Arginine and clonidine are not available in Pakistan, and L-Dopa is not routinely performed for the diagnosis of GHD in children.

Insulin-induced hypoglycemia, being the commonest test, is used in GH secretion; but the mismanagement of hypoglycemia may lead to serious complications. Initially, early in 1992, two children who died and one suffered from neurological damage after performance of GH secretion test were reported. ${ }^{15}$ Later, a number of studies have been done to explain the safety and accuracy of ITT in pediatric settings. ${ }^{16}$ However, this test is potentially dangerous and necessitates a prolong time duration in a pertinent equipped investigation unit, which makes it very expensive and unsuitable for the screening purpose outside specialised clinic. ${ }^{17}$

Multiple studies have also been done to see the diagnostic efficacy of growth hormone samples at different time intervals. This is because severe hypoglycemia is one of the potentially dangerous side effects of ITT. In one study, conducted in Thailand, the lowest level of blood sugar was achieved within 45 minutes and peak growth hormone level recorded within 90 minutes of insulin administration. So, they concluded that secure and persuasive ITT can be performed with lesser samples in short span of time. ${ }^{18}$ In another published local study, ITT observed a cost effectiveness of $29 \%$, if the 120 minutes sample is omitted. ${ }^{7,19}$ Similar result is found in this analysis, in which $47.4 \%$ patients achieved peak growth hormone levels at 60 minutes, followed by $29.9 \%$ at 90 minutes, and $19.3 \%$ at 30 minutes. It will be $24 \%$ cost-effective, if the 120 minutes sample is omitted. These results will be very helpful and beneficial in reducing costs and sampling numbers in a very expensive test, especially in developing countries.

ITT is, therefore, can be performed with lesser samples in shorter period of time in a centre fully equipped and with experienced staff. In the present study, the authors used single ITT because of the financial cost. It is suggested that the study should be conducted on larger scale with two ITTs.

\section{CONCLUSION}

Secure, cost-effective, and diagnostically accurate ITT can be accomplished with lesser samples in shorter period of time. However, this test should be performed in specialised centres by experienced staff.

\section{PATIENTS' CONSENT:}

Consents from the parents of the patients were obtained.

\section{CONFLICT OF INTEREST:}

The authors declared no conflict of interest.

\section{AUTHORS' CONTRIBUTION:}

MNI: Supervision and writeup.

NN: Data collection and analysis and basic writeup.

MN: Data collection.

TML, YNK: Data collection.

JR: Supervision.

\section{REFERENCES}

1. Hussein A, Farghaly H, Askar E, Metwalley K, Saad K, Zahran A, et al. Etiological factors of short stature in children and adolescents: Experience at a tertiary care hospital in Egypt. Ther Adv Endocrinol Metab 2017; 8(5):75-80. doi: 10.1177/2042018817707464.

2. Maghnie M, Labarta JI, Koledova E, Rohrer TR. Short stature diagnosis and referral. Front Endocrinol (Lausanne) 2018; 8:374. doi: 10.3389/fendo.2017.00374. eCollection 2017.

3. Castro LC, Rogol AD, Shulman DI. Patient information page from The Hormone Foundation. Growth hormone deficiency in children. J Clin Endocrinol Metab 2011; 96(12):A35. doi: 
10.1210/jcem.96.5.zeg35a.

4. Mehta A, Hindmarsh P. Growth hormone deficiency in children. Pharmaceutical / 2000; 264:917-21.

5. Richmond EJ, Rogol AD. Causes of short stature. UpToDate; 2019 December.

6. Wacharasindhu S, Supornsilchai V, Srivuthana S. Diagnosis and growth hormone (GH) therapy in children with $\mathrm{GH}$ deficiency: Experience in King Chulalongkorn Memorial Hospital, Thailand. J Med Assoc Thai 2007; 90(10):2047-52.

7. Lone SW, Khan YN, Qamar F, Atta I, Ibrahim MN, Raza J. Safety of insulin tolerance test for the assessment of growth hormone deficiency in children. J Pak Med Assoc 2011; 61(2):153-7.

8. Soliman A, Adel A, Sabt A, Elbukhari E, Ahmed H, De VS. Does priming with sex steroids improve the diagnosis of normal growth hormone secretion in short children? Indian J Endocrinol Metab 2014; 18(Suppl 1):S80-3. doi: 10.4103/2230-8210.145078.

9. Tenenbaum-Rakover $Y$. The need to revise the cut-off level for the diagnosis of $\mathrm{GH}$ deficiency in children. Pediatric Endocrinol Rev 2008; 5(4):880-8.

10. Pedicelli S, Peschiaroli E, Violi E, Cianfarani S. Controversies in the definition and treatment of idiopathic short stature (ISS). J Clin Res Pediatr Endocrinol 2009; 1(3):105. doi: 10.4008/jcrpe.v1i3.53.

11. Ranke MB. Towards a consensus on the definition of idiopathic short stature. Horm Res Paediatr 1996; 45(Suppl. 2):64-6. doi: 10.1159/000184851.

12. Murray PG, Dattani MT, Clayton PE. Controversies in the diagnosis and management of growth hormone deficiency in childhood and adolescence. Arch Dis Childhood 2016; 101(1):96-100. doi: 10.1136/archdischild-2014-307228.

13. Rhee N, Oh KY, Yang EM, Kim CJ. Growth hormone responses to provocative tests in children with short stature. Chonnam Med J 2015; 51(1):33-8. doi: 10.4068/cmj.2015.51.1.33.

14. Wagner IV, Paetzold C, Gausche R, Vogel M, Koerner A, Thiery J, et al. Clinical evidence-based cutoff limits for $\mathrm{GH}$ stimulation tests in children with a backup of results with reference to mass spectrometry. Eur J Endocrinol 2014; 171(3):389-97. doi: 10.1530/EJE-14-0165.

15. Shah A, Stanhope R, Matthew D. Hazards of pharmacological tests of growth hormone secretion in childhood. BMJ 1992; 304(6820):173. doi: 10.1136/bmj.304. 6820.173.

16. Galloway PJ, McNeill E, Paterson WF, Donaldson MD. Safety of the insulin tolerance test. Arch Dis Child 2002; 87(4):354-6. doi: 10.1136/adc.87.4.354.

17. Mahajan T, Lightman SL. A simple test for growth hormone deficiency in adults. J Clin Endocrinol Metab 2000; 85(4): 1473-6. doi: 10.1210/jcem.85.4.6545.

18. Jaruratanasirikul S, Leethanaporn K, Sriplung H. Should the duration of the insulin tolerance test be shortened to 90 minutes? J Pediatr Endocrinol Metab 2004; 17(8):1105-10. doi: 10.1515/jpem.2004.17.8.1105.

19. Jabbar J, Ghani F, Siddiqui I, Omair A. Diagnostic efficacy of $0,30,45,60,90$ and 120 min growth hormone samples in insulin tolerance test: Utility of growth hormone measurement at different time-points and a cost-effective analysis. Scand J Clin Lab Invest 2009; 69(3):359-64. doi: 10.1080/00365510802638707. 